\title{
Biliary cast syndrome and liver abscesses com- plicating composite multivisceral transplantation
}

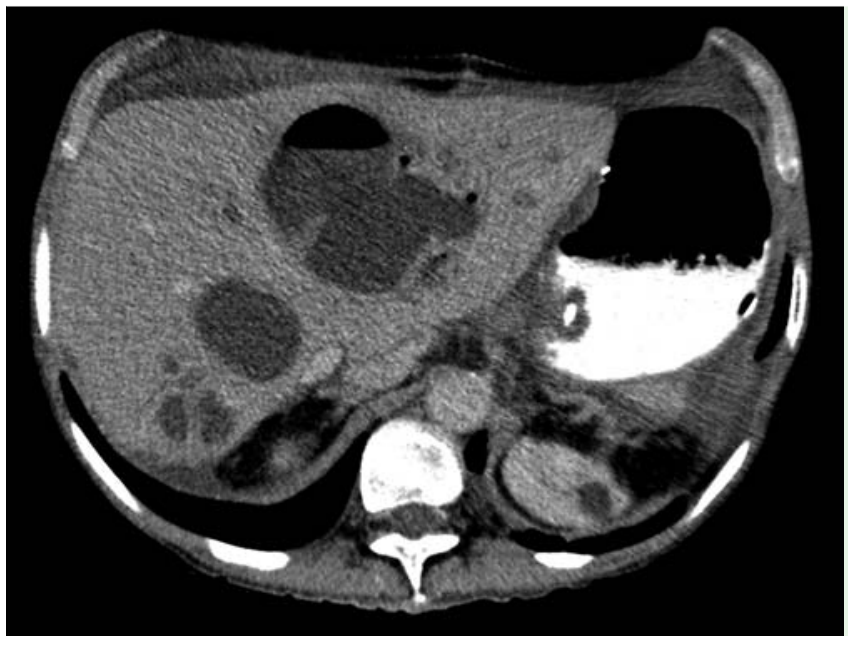

Fig. 1 Following composite multivisceral transplantation in a 59-year-old woman, a computed tomography (CT) scan showed two large hepatic abscesses with dilated intra- and extrahepatic bile ducts.

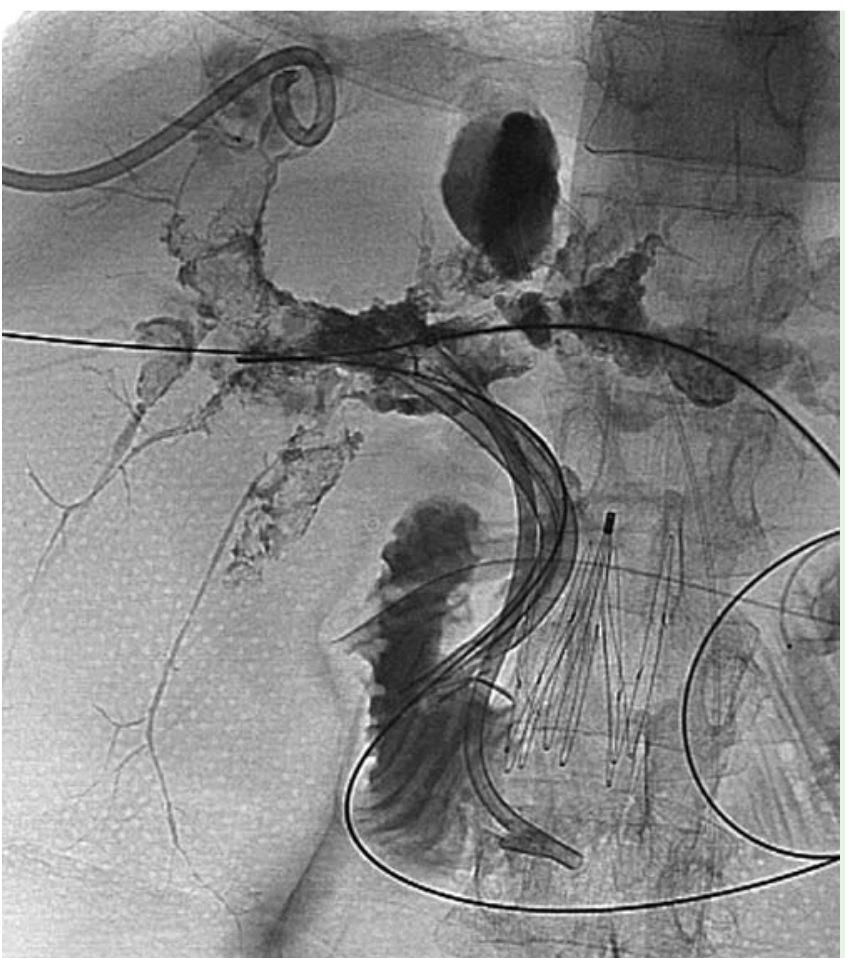

Fig. 3 Following endoscopic biliary sphincterotomy and subsequent balloon retrieval of biliary debris, a percutaneous transhepatic cholangiogram demonstrated a very dilated and severely irregular biliary tree filled with casts.

A 59-year-old woman underwent composite multivisceral transplantation as a result of cryptogenic cirrhosis and extensive thrombosis of the splanchnic vessels. She presented with obstructive jaundice with elevated liver enzymes 48 days later. A computed tomography (CT) scan ( Fig. 1) disclosed two large hepatic abscesses and dilated intra- and extrahepatic bile ducts. She underwent interventional percutaneous drainage and administration of antibiotics for the abscesses and was referred for endoscopic retrograde cholangiopancreatography (ERCP) on the following day. At ERCP, a dilated common bile duct was found with a large intraductal filling defect with extension into the intrahepatic system ( Fig. 2). Endoscopic biliary sphincterotomy was performed followed by balloon retrieval of biliary debris. Bile duct clearance was not possible and therefore plastic stents were placed. Laboratory test results did not improve. A percutaneous transhepatic cholangiogram

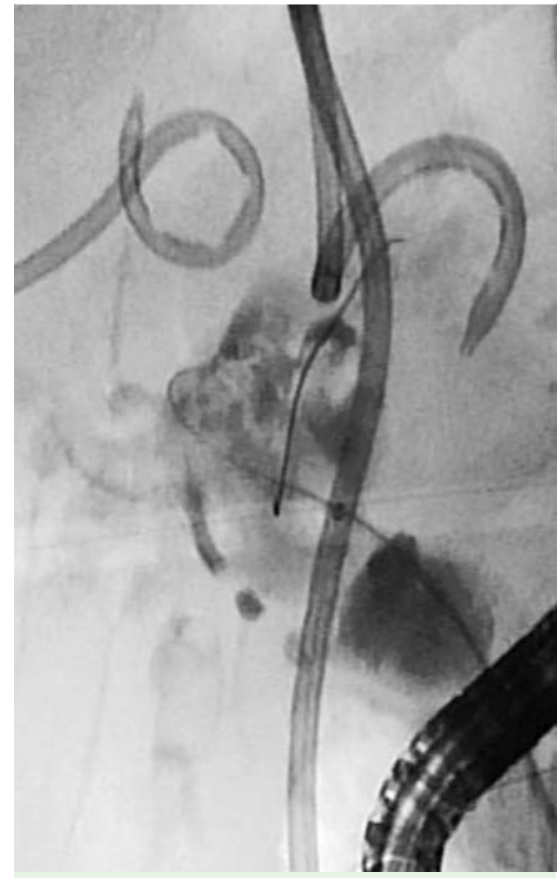

Fig.2 The patient was referred for endoscopic retrograde cholangiopancreatography. The cholangiogram revealed a dilated common bile duct with a large intraductal filling defect extending into the intrahepatic system. Note stents placed percutaneously to drain the liver abscesses.

was performed 2 weeks later demonstrating a very dilated and severely irregular biliary tree filled with casts ( Fig.3). Although the hepatic abscesses disappeared, the severe biliary tree distortion remained unresolved ( $\bullet$ Fig.4) despite repeated interventions. The graft damage was progressive and eventually the patient died after multiple complications.

Biliary cast syndrome is an entity defined by the cholangiographic findings of multiple fixed filling defects in the intra- or extrahepatic biliary tree, mirroring the luminal dimensions of the respective affected bile duct segment. Cast material can be soft or hard and may adhere to the bile duct wall. Theories concerning etiology include sloughed biliary epithelium (owing to prolonged cold ischemia or ongoing hepatic artery thrombosis), chronic rejection, infection, bile stasis, or alteration of bile metabolism [1].

The incidence varies between $2.5 \%$ and $18 \%[2,3]$ of orthotopic liver transplant 


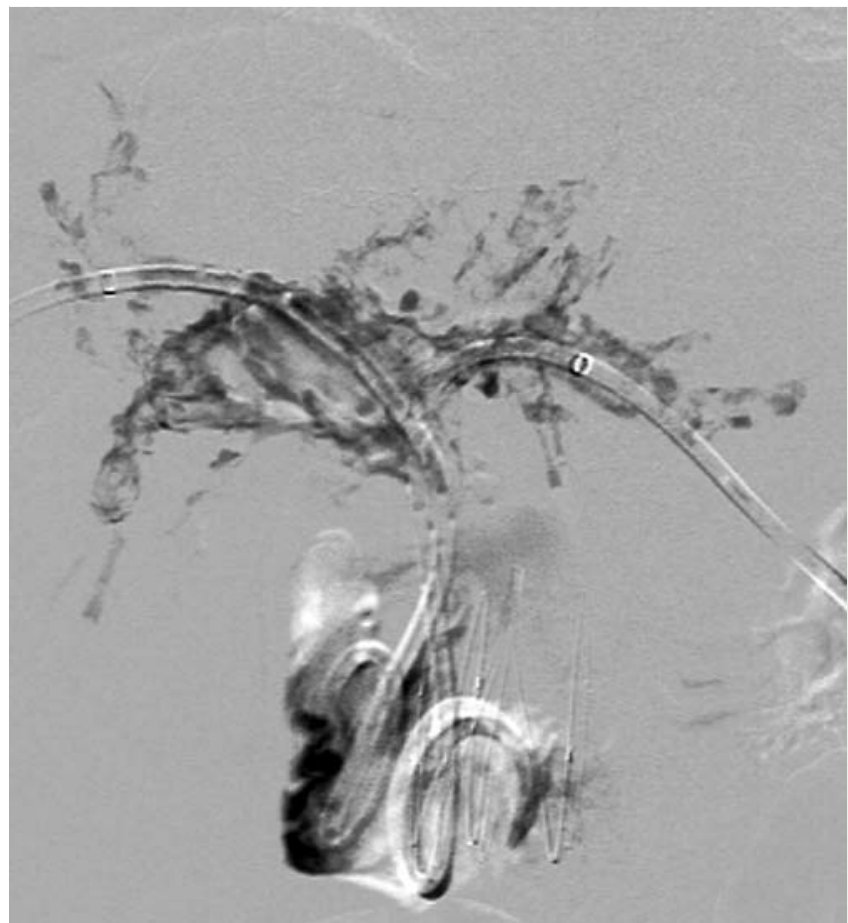

Fig. 4 The hepatic abscesses disappeared but a radiographic image indicated that the severe biliary tree distortion remained unresolved despite repeated interventions.

recipients, and retention of lithogenic material in the bile duct may lead to obstructive cholangitis and subsequent liver damage.

Limited success using ERCP or percutaneous exploration has been reported and most patients will ultimately require retransplantation [1 -4].

Endoscopy_UCTN_Code_CCL_1AZ_2AN

\section{References}

1 Pfau PR, Kochman ML, Lewis JD et al. Endoscopic management of postoperative biliary complications in orthotopic liver transplantation. Gastrointest Endosc 2000; 52: 55 63

2 Gor NV, Levy RM, Ahn J et al. Biliary cast syndrome following liver transplantation: Predictive factors and clinical outcomes. Liver Transpl 2008; 14: 1466 - 1472

3 Voigtländer T, Negm AA, Strassburg CP et al. Biliary cast syndrome post-liver transplantation: risk factors and outcome. Liver Int 2013; 33: 1287-1292

4 Srinivasaiah N, Reddy MS, Balupuri $S$ et al Biliary cast syndrome: literature review and a single centre experience in liver transplant recipients. Hepatobiliary Pancreat Dis Int 2008; 7: 300-303

\section{Bibliography}

DOI http://dx.doi.org/

10.1055/s-0034-1377636

Endoscopy 2014; 46: E536-E537

(c) Georg Thieme Verlag KG

Stuttgart · New York

ISSN 0013-726X

Corresponding author Fernanda Prata Martins, MD, PhD

Rua Barata Ribeiro 490 cj 118

Zip Code: 01308-000

Sao Paulo - SP

Brazil

Fax: +55-11-30622566

fernandapbm@gmail.com 